\title{
Exploring a novel multifunctional agent to improve the dispersion of short aramid fiber in polymer matrix
}

\author{
G. S. Shibulal, K. Naskar* \\ Rubber Technology Centre, Indian Institute of Technology, Kharagpur-721302, West Bengal, India
}

Received 28 september 2011; accepted in revised form 19 November 2011

\begin{abstract}
Composites based on resorcinol formaldehyde latex (RFL) coated aramid short fiber and a polyolefin based thermoplastic elastomer, namely ethylene octene copolymer (EOC) were prepared by melt mixing technique. The effects of both fiber loading and its length on the mechanical and thermal characteristics of the composite under natural and sheared conditions were investigated. Both the low strain modulus and Young's modulus were increased as a function of fiber loading and length. However, thermal stability of the composite was found to enhance with increase in fiber loading and was independent of fiber length. Due to poor interfacial interaction between the fiber and the matrix and the formation of fiber aggregation especially with $6 \mathrm{~mm}$ fiber at high loading, the elongation and toughness of the composite were found to decrease drastically. In order to solve this problem, a maleic anhydride adducted polybutadiene (MA-g-PB) was applied on the aramid fiber. The improvements in tensile strength, elongation at break, toughness to stiffness balance and a good quality of fiber dispersion especially with $6 \mathrm{~mm}$ short fiber were achieved. These results indicate the potential use of maleic anhydride adducted PB as a multifunctional interface modifying coupling agent for the aramid short fiber reinforced polymers to enhance the mechanical properties as well as fiber dispersion. FTIR analyses of the treated fiber and SEM analyses of the tensile fractured surfaces of the composite strongly support and explain these results.
\end{abstract}

Keywords: reinforcements, thermoplastic elastomer, short fiber, multifunctional agent, mechanical properties

\section{Introduction}

Polyolefin based thermoplastic elastomers (TEO) have received considerable attention due to their chemical inertness, low density and low cost compared to other thermoplastic elastomers (TPEs). Ethylene octene copolymer (EOC) is a new class of polyolefin based metallocene catalyzed thermoplastic elastomers, which have recently gained much attention because of their random comonomer distribution, narrow molecular weight distribution and a controlled level of long chain branching $[1,2]$. Moreover these are available in pellet form that helps in easy handling, faster mixing and compounding. Compared to the well known conventional polyolefin elastomer EPDM, EOC exhibits faster mixing and better dispersion when blending with thermoplastics like PP, PE etc. The structure and properties of a random ethylene octene copolymer strongly depends on the composition of ethylene and 1-octene as well as the condition of crystallization. The crystallinity decreases with increasing concentration of the comonomer 1-octene. The yield stress and the modulus at higher strain decrease as the comonomer content of EOC increases, which is due to the decreasing crystallinity. The low crystalline ethylene 1-octene copolymers behave like TPE by exhibiting a stress-strain curve similar to TPE. The use of this polymer has been tested very successfully as an impact modifier for PP by many researchers [3-5]. Recently our research group studied the use of EOC as an alternative for the traditional EPDM/PP blend and developed a new class

\footnotetext{
${ }^{*}$ Corresponding author, e-mail: knaskar@rtc.iitkgp.ernet.in (c) BME-PT
} 
of EOC/PP based thermoplastic vulcanizates (TPVs) by the dynamic vulcanization process with peroxide assisted co-agents [6-7]. EOC and functionalized EOC find application as an impact modifier to other polar and brittle thermoplastics also. Chapleau et al. reported the impact modification of polyethylene terephthalate (PET) with an Engage grade of EOC by chemical compatibilization of the two with the addition of glycidyl methacryalate (GMA) grafted polyolefins [8]. Aróstegui and Nazábal [9] developed a super tough polybutylene terephthalate (PBT) by melt blending with $20 \%$ EOC and different levels of difunctional epoxy resin in a twin screw extruder followed by injection molding. The impact modification of polyacetal (POM) with EOC by dynamic vulcanization with dicumyl peroxide was reported by Uthaman et al. [10]. Guerrica et al. developed an EOC toughned polymethylene terephthalate (PMT) compatibilised with partially malenized EOC [11]. Yu et al. [12] preapared a super tough Nylon 6 by using maleated EOC as a toughener. Though EOC enhances the low temperature impact resistance for both the commodity thermoplastics like polypropylene and engineering thermoplastics like PET, Nylon, POM etc, the sole use of this TPE is limited for load bearing and high temperature engineering applications because of its poor mechanical properties especially low strain modulus, poor dimensional stability and low thermal stability. Reinforcing the EOC with proper reinforcing agent, which can enhance both strength and thermal stability is one of the ways to overcome this problem. The reinforcement of thermoplastic elastomers with short fibers have gained much attention in the recent times, since it can reinforce the matrix and can give good strength and stiffness comparatively with a low volume fraction of fibers [13]. Moreover, the TPE-short fiber composites can be recycled easily. Among the short fibers available, aramid is one of the good candidates in the short fiber arena. These kinds of fibers have a unique combination of strength, stiffness and high temperature stability. However, it shows lesser mechanical bonding (adhesion) with the polymer matrix. The application of chemical treatment like $\mathrm{N}$-alkylation, RFL dipping, plasma treatment and polymer grafting to improve surface roughness and to bring various functional groups on the fiber surface is highly required for these kinds of fibers to improve the adhesion with the elastomeric matrix. Generally, for polar fibers like Rayon, Nylon etc. sufficient rubber adhesion is achieved by treating and curing the fiber with resorcinol formaldehyde latex (RFL) dip prior to its incorporation in the rubber matrix. The resorcinol formaldehyde (RF) component promotes adhesion to the cord via polar or covalent interaction, while the dried latex (L) co-vulcanizes with the rubber matrix ensuring adhesion to that matrix. For aramid fibers, simple treatment with RFL leads to rubber composite exhibiting low fiber to matrix adhesion with failure often occurring at the fiberRFL dip interface. This is due to the physical structure of the aramid, which being highly crystalline provides an uninviting surface to the components making up the RFL. Excellent aramid to rubber adhesion can be achieved by first activating the aramid with low molecular weight and highly reactive epoxies prior to RFL treatment. These kinds of treatment on the fiber surfaces impart some roughness on the fiber surface, which allows more micromechanical interlocking between the polymer and the fiber leading to higher bond strength even though other interactions may be weak [14-16]. The use of a reactive compatibilizer like maleic anhydride grafted polymer with a non polar part having a structure similar to the polymer matrix is also used to bring fiber-matrix interaction in aramid fiber reinforced composites [17]. Many researchers have reported various studies carried out with different kinds of aramid short fibers on a variety of thermoplastic elastomers. Arroyo and Bell [18] reported the morphology/behavior and recyclability of the Twaron ${ }^{\circledR}$ fiber reinforced PP/EPDM TPE. Kutty and coworkers $[19,20]$ extensively studied various aspects of $\operatorname{Kevlar}^{\circledR}$ short fiber reinforced polyurethane based thermoplastic elastomer systems. Recently Akbarian et al. [21] reported dynamic mechanical and rheological behavior of a Twaron fiber reinforced ester based thermoplastic polyurethane. However, only very few literatures are available regarding the reinforcement studies of EOC with short fibers $[22,23]$. There seems to be no previous studies made on the reinforcement aspects of ethylene-octene copolymers with any kind of aramid short fiber in general and short RFL coated Technora aramid fiber in particular. Very recently the authors [24] have reported on the mechanical, morphological and rheological behavior of EOC 
with RFL dipped Technora aramid short fiber having a fixed aspect ratio and the effectiveness of MA-g-PB as a compatibilising agent between the fiber and the EOC matrix. The present paper focuses on the mechanical and thermomechanical properties of EOC reinforced with aramid fiber having different aspect ratios at different loading levels with special reference to fiber orientations and the effect of a low molecular weight maleic anhydride grafted 1,2 polybutadiene (MA-g-PB) as an interface modifier to maintain toughness to stiffness balance at higher fiber loading.

\section{Experimental}

\subsection{Materials}

Ethylene octene copolymer (trade name EXACT ${ }^{\circledR}$ 5061 (specific gravity of $0.868 \mathrm{~g} / \mathrm{cc}$ at $23^{\circ} \mathrm{C}$; comonomer (octene) content of $13 \%$; melting temperature $\left(T_{\mathrm{m}}\right)$ of $52.8^{\circ} \mathrm{C}$, melt flow index (MFI) of 0.5 at $190^{\circ} \mathrm{C} / 2.16 \mathrm{~kg}$ was procured from Exxon Mobil Chemical Company, USA. Aramid short fiber (trade name Technora ${ }^{\circledR}$ ) with a chemical name copoly(paraphenylene/3, 4'-oxydiphenylene terephthalamide) was obtained from Teijin Aramid BV, The Netherlands. The detail specifications of the fiber are given in Table 1. Maleic anhydride adducted 1,2 polybutadiene (trade name Ricon ${ }^{\circledR} 131$ MA5) having a number average molecular weight $\left(M_{\mathrm{n}}\right)$ of 5300 , a specific gravity of $0.9 \mathrm{~g} / \mathrm{cc}$ and maleic anhydride content of $5 \%$ was obtained from Sartomer Company, USA.

Table 1. Technical specifications of technora ${ }^{\circledR}$ (RFL coated aramid short fiber)

\begin{tabular}{|l|c|}
\hline \multicolumn{1}{|c|}{ Parameter / Properties } & Value \\
\hline Colour & Gold \\
\hline Specific gravity & 1.39 \\
\hline Equillibrium moisture regain $[\%]$ & 2 \\
\hline Average fiber length $[\mathrm{mm}]$ & $1 / 3 / 6$ \\
\hline Diameter $[\mu \mathrm{m}]$ & $10-12$ \\
\hline Average aspect ratio $[L / D$ ratio] & $91 / 275 / 550$ \\
\hline Young's modulus $[\mathrm{GPa}]$ & $20-21$ \\
\hline Tensile strength $[\mathrm{MPa}]$ & $3000-3500$ \\
\hline Elongation at break $[\%]$ & $5-7$ \\
\hline
\end{tabular}

\subsection{Preparation of composites}

Formulations used for the preparation of the composites are given in Table 2. The short fiber loading was varied from 1 to $10 \mathrm{phr}$. All the composites were prepared by melt mixing of the components in
Table 2. Formulations of the mixes in phr (parts per hundred rubber)

\begin{tabular}{|c|c|c|c|}
\hline $\begin{array}{c}\text { Sample } \\
\text { designation }\end{array}$ & $\begin{array}{c}\text { Short fiber } \\
\text { length } \\
{[\mathrm{mm}]}\end{array}$ & $\begin{array}{c}\text { Short fiber } \\
\text { loadings } \\
\text { [phr] }\end{array}$ & $\begin{array}{c}\text { MA-g-PB } \\
\text { [phr] }\end{array}$ \\
\hline $1 \mathrm{RAF}_{3}$ & 1 & 3 & - \\
\hline $1 \mathrm{RAF}_{5}$ & 1 & 5 & - \\
\hline $1 \mathrm{RAF}_{10}$ & 1 & 10 & - \\
\hline $3 \mathrm{RAF}_{3}$ & 3 & 3 & - \\
\hline $3 \mathrm{RAF}_{5}$ & 3 & 5 & - \\
\hline $3 \mathrm{RAF}_{10}$ & 3 & 10 & - \\
\hline $6 \mathrm{RAF}_{3}$ & 6 & 3 & - \\
\hline $6 \mathrm{RAF}_{5}$ & 6 & 5 & - \\
\hline $6 \mathrm{RAF}_{10}$ & 6 & 10 & - \\
\hline $6 \mathrm{RAF}_{10} \mathrm{C}_{3}$ & 6 & 10 & 3 \\
\hline $6 \mathrm{RAF}_{20} \mathrm{C}_{3}$ & 6 & 20 & 3 \\
\hline
\end{tabular}

${ }^{*} \mathrm{RAF}$ indicates RFL coated aramid fiber, left side Arabic number indicate fiber length in $\mathrm{mm}$ and the subscript number indicates its concentaration in phr, C stands for the interface modifying coupling agent and the subscript number indicates its concentration in phr.

a Haake Rheomix 600 OS internal mixer having a chamber volume of $85 \mathrm{~cm}^{3}$ at a temperature of $80^{\circ} \mathrm{C}$ with a rotor speed of $80 \mathrm{rpm}$ for 10 minutes. In order to achieve better dispersion, half portion of the polymer was first melted for one minute and to this half portion of fiber was added and the mixing was continued for another one minute. The sequence is again repeated for 2 to 3 min with the remaining portion of polymer and the mixing was continued up to $10 \mathrm{~min}$ after adding remaining portion of the fiber at $3^{\text {rd }}$ min at a constant rotor speed of $80 \mathrm{rpm}$. The modifier (MA-g-PB) was incorporated by first warming the modifier at $70-80^{\circ} \mathrm{C}$ and then added dropwise to the short fiber taken in a flask/beaker and stirring with a magnetic stirrer at $100^{\circ} \mathrm{C}$ for 10 minute at low speed. The compatibilizer/fiber mix is then added into the mixing chamber containing the molten polymer at the $2^{\text {nd }} \min$ in one stretch and continued the mixing up to $10 \mathrm{~min}$ at the same rpm. After the mixing is over, the composite was discharged and passed through a two roll mill once to get a flat sheet. The sheet was then pressed in a compression molding press (Moore Press, Birmingham, UK) at $100^{\circ} \mathrm{C}$ for $3 \mathrm{~min}$ at a pressure of $7 \mathrm{MPa}$ and then cooled down to room temperature under the same pressure by circulating cold water to get randomly oriented fiber composites (composites in unsheared condition). Composites with a high degree of fiber orientation (composites in sheared condition) were prepared by extrusion of the fiber/matrix 
Table 3. Processing conditions followed for the extrusion of the composite

\begin{tabular}{|c|c|c|c|c|c|c|c|}
\hline Processing conditions & Zone-1 & Zone-2 & Zone-3 & Zone-4 & Zone-5 & Zone-6 & Die exit \\
\hline Temperature $\left[{ }^{\circ} \mathrm{C}\right]$ & 70 & 75 & 80 & 90 & 100 & 100 & 100 \\
\hline Screw [rpm] & 80 & -- & - & 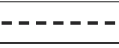 & 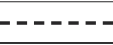 & . & \\
\hline
\end{tabular}

blend through a circular die using a twin screw extruder fitted with Haake Rheomix 600 OS. The processing conditions followed for this extrusion are presented in Table 3. Extrudate were cut, stacked side by side and compression molded using the same conditions mentioned above.

\subsection{Characterization of the composites Mechanical properties}

The dumb-bell shaped specimens of the composites in parallel and perpendicular directions with respect to the mill direction used for testing were die cut from the compression molded sheet and the testing was done after 24 hours of maturation at room temperature. Tensile properties were measured according to ASTM D 412-98A using a universal testing machine Hounsfield H10KS (UK) at a constant cross-head speed of $500 \mathrm{~mm} / \mathrm{min}$. All the values were averages of three measurements.

\section{Spectroscopic characterization}

Fourier transform infrared (FTIR) spectra were recorded in the range of $400-4500 \mathrm{~cm}^{-1}$ using a Perkin-Elmer FTIR Spectrometer (model Spectrum RX-I) with a resolution of $4 \mathrm{~cm}^{-1}$. Films of approximately $0.1 \mathrm{~mm}$ thickness were obtained by compression molding 1-2 gram sample using a laboratory press (temperature: $100^{\circ} \mathrm{C}$ and pressure $7 \mathrm{MPa}$ ).

\section{Dynamic Mechanical Thermal Analyses (DMTA)}

Dynamic mechanical thermal properties of the composites were measured using a dynamic mechanical thermal analyser (DMTA 2980 V1.7B, TA instruments, USA) in dual cantilever mode. The temperature sweep study was made from -80 to $+80^{\circ} \mathrm{C}$ at a heating rate of $3^{\circ} \mathrm{C} /$ minute and a frequency of $1 \mathrm{~Hz}$. The storage modulus and loss tangent were recorded for all the samples under identical conditions.

\section{Thermal Degradation Studies (TGA)}

Thermal stability of the composites were measured by thermogravimetric analyses (TGA) using Q50 V6.1 series, TA instruments (New Castle, Delaware), from ambient temperature to $600^{\circ} \mathrm{C}$ at a pro- grammed heating rate of $10^{\circ} \mathrm{C} / \mathrm{min}$ under nitrogen atmosphere. A sample weight of 8-10 mg was taken for all the investigation. The weight loss against temperature was recorded.

Morphological Analysis- Tensile fractured samples of the composites were analysed using a JEOL (JSM 5800, Japan) scanning electron microscope (SEM). The samples were sputter coated with gold prior to the analyses.

\section{Results and discussion}

\subsection{Effect of short fiber loading on the mixing} characteristics and mechanical properties

The mixing torque-time relationship of the EOC/ short fiber composite as a function of short fiber loading and length is shown in Figure 1 and Table 4. The characteristics of these torque curves show high initial torque with irregular broad peaks from 0 to 4 minutes, is due to the sequential feeding of the matrix material in the pellet form followed by the

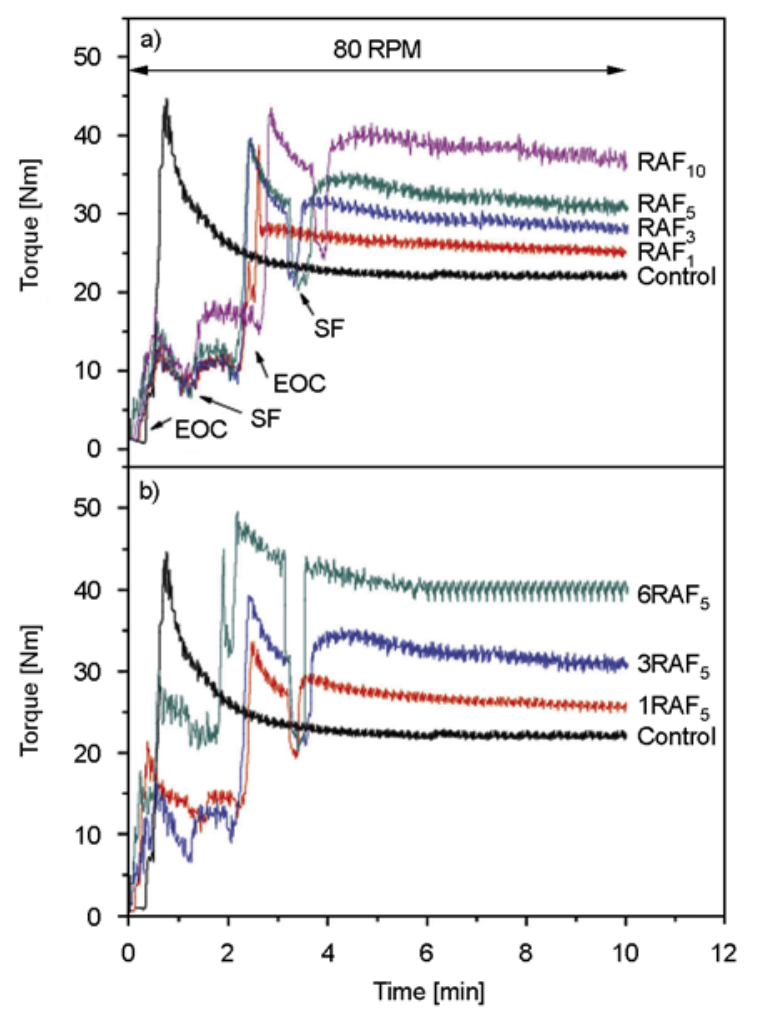

Figure 1. Mixing torque-time relationship of EOC/short fiber composites (a) as a function of short fiber loading (b) as a function of short fiber length 
Table 4. Mixing characteristics of EOC/SF composites in Haake rheomix

\begin{tabular}{|l|c|c|c|}
\hline Mix code & $\begin{array}{c}\text { Torque at } \\
\mathbf{1 0}^{\text {th }} \text { minute } \\
{[\mathbf{N m}]}\end{array}$ & Delta torque & $\begin{array}{c}\text { Melt temperature } \\
\text { at dumping } \\
{[\mathbf{N m}]}\end{array}$ \\
\hline Control & 21.8 & - & 122.3 \\
\hline $3 \mathrm{RAF}_{3}$ & 28.6 & 6.8 & 130.5 \\
\hline $3 \mathrm{RAF}_{5}$ & 30.5 & 8.7 & 133.0 \\
\hline $3 \mathrm{RAF}_{10}$ & 36.3 & 14.5 & 142.7 \\
\hline $1 \mathrm{RAF}_{5}$ & 25.5 & 3.7 & 126.3 \\
\hline $6 \mathrm{RAF}_{5}$ & 40.9 & 19.1 & 142.2 \\
\hline
\end{tabular}

incorporation of dry fiber. As per the mixing sequence, the ram has to be open at the end of $1^{\text {st }}$, $2^{\text {nd }}$ and $3^{\text {rd }}$ minutes of mixing. Since the torque sensing is a continuous process throughout the mixing cycle, it shows a lower torque at these points. The mixing torque starts to stabilize immediately and shows a plateau region of nearly constant mixing torque after all the mixing sequence is over. The stabilized torque value of the polymer/fiber composite and the melt temperature were found to increase with increase in both short fiber loading and length. The torque is seen to increase progressively to approximately $67 \%$ of pure EOC when $10 \mathrm{phr}$ of $3 \mathrm{~mm}$ short fiber is added to the matrix melt. At a constant loading of $5 \mathrm{phr}$, for 1, 3 and $6 \mathrm{~mm}$ short fibers the percentage rise of torque with respect to the pure EOC were 17, 40 and $88 \%$ respectively. This effect may be explained with the change in melt viscosity of the polymer fiber composite as a result of fiber addition. Fibers, when added into polymer melt tend to perturb the normal flow of the pure EOC melt by hindering the mobility of chain segments in flow [25]. This results in a fiber filled system with a higher melt viscosity than the pure polymer. Increasing the fiber content and aspect ratio (here aspect ratio varies only because of increased fiber length) further restrict polymer flow which leads to an increased viscosity of the EOC/short fiber suspension. Since viscosity is directly related to torque (at constant temperature and rotor speed), it requires higher torque for compounding. The increase in the melt temperature with increase in short fiber loading and length can be thought of frictioning between the fiber and the polymer and between fibers during the shear mixing.

\subsection{Mechanical properties of the composites}

(a) Effect of short fiber length and loading

Fiber length, more precisely the aspect ratio of the fiber (ratio between the length and diameter of the fiber) and its concentration are some of the most important parameters controlling the mechanical properties of the composites. Fiber length influences the extent of load transfer from matrix to fiber. The minimum fiber length at which the extent of load transfer is maximum is called the critical fiber length. If the fiber length is less than the critical fiber length, the stress transfer from the matrix to the fiber will not be effective as a result the reinforcement will be insufficient. On the other hand, if the fiber length is greater than the critical fiber length, the shear stress transfer across the interface

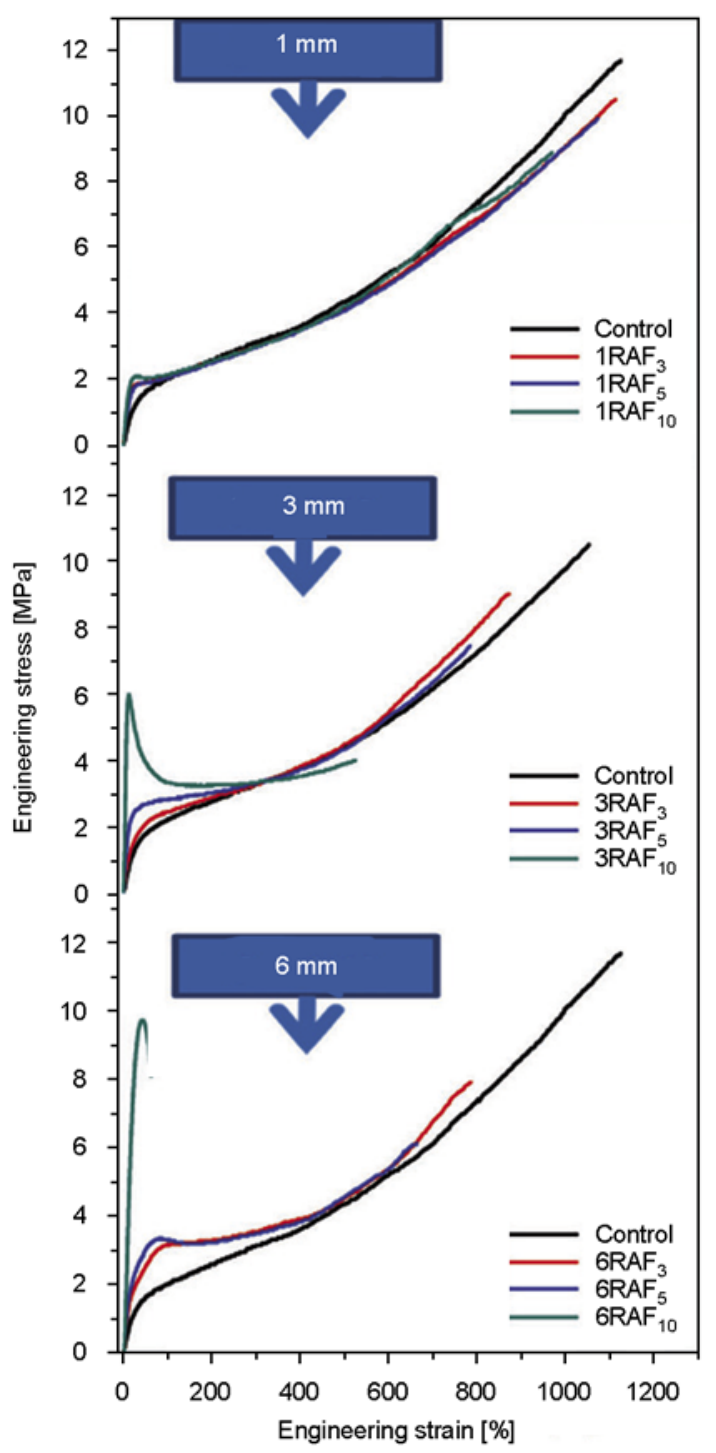

Figure 2. Stress-strain curves of EOC/short fiber composite as a function of fiber loading and length 
from matrix to the fiber will build up sufficient tensile stress in the fiber to its tensile strength leading to fiber fracture. Furthermore, the high length fibers may undergo entanglement with each other causing aggregate lumps of fibers which act as stress concentrated points, as a result the stressed composite leads to a low strain failure or brittle failure [2628]. The stress-strain behavior and the corresponding tensile properties such as tensile strength, elongation at break, Young's modulus, low strain modulus $(10 \%)$ and high strain modulus $(100 \%)$ as a function of short fiber length and loading are displayed in Figure 2 and Table 5 respectively. Pristine EOC shows a stress-strain curve with a strain hardening effect $[29,30]$. Addition of $1 \mathrm{~mm}$ short fiber, even at a loading of $10 \mathrm{phr}$ does not make any impact of the inherent strength and modulus of the short fiber on EOC matrix. In other words, incorporation of $1 \mathrm{~mm}$ short fiber does not alter the original deformation behavior of the neat EOC to a greater extent. This means that Technora is not effectively reinforcing the EOC matrix at a fiber length of $1 \mathrm{~mm}$ even at a concentration of $10 \mathrm{phr}$. This may be due to the insufficient stress transfer from matrix to fiber because of the low aspect ratio of the fiber (average aspect ratio of $1 \mathrm{~mm}$ short fiber is only 96) and the inability to make a pronounced micromechanical interlocking between the fiber and the matrix [31]. With the addition of $3 \mathrm{~mm}$ short fiber having an average aspect ratio of 275 , impart a significant improvement in low strain modulus at a fiber loading of $10 \mathrm{phr}$. The deformation behavior of $10 \mathrm{phr} 3 \mathrm{~mm}$ fiber loaded composite shows different characteristics regions such as a well pronounced linear elastic region; a yielding followed by a drop in stress, a short plastic deformation region followed by an increase in stress and finally fracture. This is a synonymous stress strain behavior of a semi crystalline polymer. This can be attributed that as the aspect ratio of the fiber increases, there is a possibility of more mechanical interlocking between the fiber and the polymer. As a result of this higher force is required to cause an initial deformation which is responsible for the high stress value in the low strain region. The moment at which the disentanglement occurs between the polymer and the short fiber beyond the yield point it experiences a sudden drop in the stress. The orientations of the short fibers in the direction of force at higher deformation are responsible for the further increase in the stress. In other words, $3 \mathrm{~mm}$ short fiber even at a loading of $10 \mathrm{phr}$ allows the inherent onset of strain hardening behavior of the virgin EOC matrix at high deformation (greater than 300\%). Incorporation of $6 \mathrm{~mm}$ short fiber with an average aspect ratio of 550 also exhibit more or less similar kind of deformation behavior as in the case of $3 \mathrm{~mm}$ fiber loaded composite up to a fiber loading of $5 \mathrm{phr}$.

Table 5. The mechanical properties of the RFL coated short fiber/EOC composites as a function of fiber length and loading in natural condition (witout any fiber orientation)

\begin{tabular}{|c|c|c|c|c|c|c|c|}
\hline \multicolumn{2}{|c|}{$\begin{array}{c}\text { Sample ID with mill } \\
\text { direction }\end{array}$} & $\begin{array}{c}\text { TS } \\
{[\mathrm{MPa}]}\end{array}$ & $\begin{array}{c}\text { Elongation } \\
{[\%]}\end{array}$ & $\begin{array}{l}\text { M 10\% } \\
{[\mathrm{MPa}]}\end{array}$ & $\begin{array}{c}\text { M 100\% } \\
\text { [MPa] }\end{array}$ & $\begin{array}{c}\text { Young's modulus } \\
\text { [MPa] }\end{array}$ & $\begin{array}{l}\text { Hardness } \\
\text { [Shore A] }\end{array}$ \\
\hline \multicolumn{2}{|c|}{ Control } & $10.9 \pm 0.6$ & $1132 \pm 65$ & $0.55 \pm 0.06$ & $2.1 \pm 0.08$ & $4.7 \pm 0.3$ & $77 \pm 0$ \\
\hline \multirow{2}{*}{$1 \mathrm{RAF}_{3}$} & $\mathrm{~L}$ & $10.1 \pm 0.5$ & $1020 \pm 65$ & $0.67 \pm 0.04$ & $2.2 \pm 0.05$ & $5.7 \pm 0.9$ & \multirow{2}{*}{$81 \pm 1$} \\
\hline & $\mathrm{T}$ & $9.9 \pm 0.7$ & $1040 \pm 58$ & $0.69 \pm 0.03$ & $2.1 \pm 0.03$ & $5.9 \pm 0.8$ & \\
\hline \multirow{2}{*}{$1 \mathrm{RAF}_{5}$} & $\mathrm{~L}$ & $9.6 \pm 0.7$ & $1083 \pm 21$ & $1.10 \pm 0.08$ & $2.1 \pm 0.06$ & $9.0 \pm 0.9$ & \multirow{2}{*}{$84 \pm 1$} \\
\hline & $\mathrm{T}$ & $9.4 \pm 0.6$ & $1062 \pm 31$ & $1.21 \pm 0.10$ & $2.2 \pm 0.05$ & $8.9 \pm 0.8$ & \\
\hline \multirow{2}{*}{$1 \mathrm{RAF}_{10}$} & $\mathrm{~L}$ & $9.0 \pm 0.9$ & $1056 \pm 75$ & $1.40 \pm 0.07$ & $2.3 \pm 0.14$ & $11.1 \pm 1.3$ & \multirow{2}{*}{$89 \pm 2$} \\
\hline & $\mathrm{T}$ & $8.9 \pm 0.8$ & $1040 \pm 60$ & $1.30 \pm 0.04$ & $2.4 \pm 0.09$ & $10.8 \pm 1.4$ & \\
\hline \multirow{2}{*}{$3 \mathrm{RAF}_{3}$} & $\mathrm{~L}$ & $8.9 \pm 0.3$ & $860 \pm 32$ & $0.83 \pm 0.20$ & $2.5 \pm 0.08$ & $8.2 \pm 0.06$ & \multirow{2}{*}{$83 \pm 1$} \\
\hline & $\mathrm{T}$ & $9.0 \pm 0.3$ & $863 \pm 27$ & $0.86 \pm 0.04$ & $2.5 \pm 0.09$ & $11.7 \pm 1.0$ & \\
\hline \multirow{2}{*}{$3 \mathrm{RAF}_{5}$} & $\mathrm{~L}$ & $8.1 \pm 0.7$ & $810 \pm 24$ & $1.67 \pm 0.16$ & $2.7 \pm 0.08$ & $17.2 \pm 2.6$ & \multirow{2}{*}{$86 \pm 1$} \\
\hline & $\mathrm{T}$ & $8.5 \pm 0.6$ & $792 \pm 47$ & $1.42 \pm 0.91$ & $2.7 \pm 0.08$ & $21.2 \pm 1.5$ & \\
\hline \multirow{2}{*}{$3 \mathrm{RAF}_{10}$} & $\mathrm{~L}$ & $5.8 \pm 0.8$ & $595 \pm 97$ & $5.10 \pm 0.46$ & $3.6 \pm 0.14$ & $53.0 \pm 3.7$ & \multirow{2}{*}{$92 \pm 2$} \\
\hline & $\mathrm{T}$ & $5.9 \pm 0.9$ & $615 \pm 87$ & $4.70 \pm 0.80$ & $3.5 \pm 0.21$ & $48.4 \pm 4.2$ & \\
\hline \multirow{2}{*}{$6 \mathrm{RAF}_{3}$} & $\mathrm{~L}$ & $7.8 \pm 0.6$ & $745 \pm 49$ & $0.91 \pm 0.04$ & $2.8 \pm 0.09$ & $11.2 \pm 3.0$ & \multirow{2}{*}{$83 \pm 1$} \\
\hline & $\mathrm{T}$ & $7.5 \pm 0.5$ & $730 \pm 38$ & $0.93 \pm 0.07$ & $3.0 \pm 0.07$ & $13.4 \pm 2.5$ & \\
\hline \multirow{2}{*}{$6 \mathrm{RAF}_{5}$} & $\mathrm{~L}$ & $6.9 \pm 0.9$ & $662 \pm 43$ & $1.20 \pm 0.10$ & $3.3 \pm 0.07$ & $19.0 \pm 3.5$ & \multirow{2}{*}{$88 \pm 2$} \\
\hline & $\mathrm{T}$ & $7.1 \pm 0.9$ & $640 \pm 61$ & $1.40 \pm 0.16$ & $3.2 \pm 0.07$ & $22.6 \pm 2.7$ & \\
\hline \multirow{2}{*}{$6 \mathrm{RAF}_{10}$} & $\mathrm{~L}$ & $9.8 \pm 0.9$ & $57 \pm 21$ & $5.60 \pm 0.82$ & - & $67.0 \pm 5.1$ & \multirow{2}{*}{$94 \pm 2$} \\
\hline & $\mathrm{T}$ & $5.2 \pm 0.7$ & $120 \pm 28$ & $5.80 \pm 1.20$ & $4.2 \pm 0.92$ & $56.0 \pm 4.5$ & \\
\hline
\end{tabular}


However, at $10 \mathrm{phr}$ fiber loading, it shows a steep rise in the stress at a low strain level (20\%). This steep rise in stress at low strain level at $10 \mathrm{phr}$ of fiber loading compared to 1 and $3 \mathrm{~mm}$ fiber loaded composites can be attributed to the fact that more efficient stress transfer is taking place in the case of $6 \mathrm{~mm}$ short fiber filled composite. However, the fiber aggregates developed in the composites due to the improper fiber dispersion of the $6 \mathrm{~mm}$ fiber act as a point of weakness which leads to a brittle kind of failure by the application of strain.

\section{(b) Effect of fiber orientations}

The performance of any short fiber reinforced polymer composite is depend upon the extent of fiber orientations. The efficiency of stress transfer is higher if the fibers are oriented parallel to the direction of application of force [32]. The tensile properties of a $10 \mathrm{phr}$ loaded composites in longitudinal (L) and transverse (T) directions as a function of fiber length is shown in Table 6. The orientation effect of low fiber loaded composites are not considered here because, at low fiber loading, though they are oriented in the flow direction when they are allowed to pass through a $2 \mathrm{~mm}$ extrudate die as shown in Figure 3, the fibers can easily move around and lose their orientations during mold flow in the molding operations. Since the movement of fiber is restricted at high fiber loading during com-

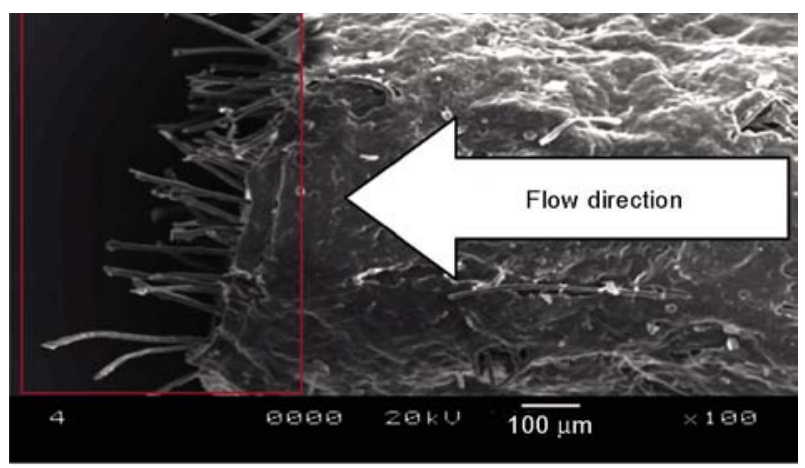

Figure 3. SEM Photomicrograph of the cross sectional view of the extrudate of a $5 \mathrm{phr} 3 \mathrm{~mm}$ short fiber filled composite pression molding, the percentage orientation will be more in high fiber loaded composite. The optical micrograph of a $3 \mathrm{~mm} 5 \mathrm{phr}$ and $10 \mathrm{phr}$ loaded composites are shown in Figure 4a-d gives qualitative information of fiber orientation of the composite in their natural and sheared condition respectively. The mechanical properties displayed in Table 6 , it is clear that $1 \mathrm{~mm}$ fiber does not make much impact on the properties due to poor orientation where as 3 and $6 \mathrm{~mm}$ fiber loaded composite, the properties such as tensile strength, low strain modulus and Young's modulus were always higher in longitudinal direction than the composites with transverse fiber orientations.

\section{(c) Effect of $M A-g-P B$}

The behavior and performance of a short fiber/polymer composite cannot be explained only in terms of the specific properties of its components such as the fiber and the matrix. The interface that exists between the fiber and the matrix is also a main component of the composite. A strong interfacial adhesion between fiber and matrix is a precondition for transfer load from matrix to fiber. An extremely weak fiber/matrix interface may result in complete fiber interfacial debonding and pullout, producing a significant loss in composite strength with no or minimal improvement in composite toughness [3335]. From the analyses of the mechanical properties of EOC/Short fiber composites, it is understood that the tensile strength and break elongation of the composite decreases as a function of fiber loading. This may be due to the inability to form a good interface between the fiber and the EOC matrix due to a huge polarity mismatch between the two. A drastic decrease in the break elongation and a brittle kind of failure at a very low strain in the case of a $10 \mathrm{phr} 6 \mathrm{~mm}$ fiber loaded composite may be due to the aggregate formation because of the fiber entanglement at higher fiber loading. In order to find a solution for both the poor interfacial adhesion between the EOC and the fiber and the poor fiber

Table 6. Mechanical properties of $10 \mathrm{phr}$ short fiber loaded composites in sheared condition (after orientations)

\begin{tabular}{|l|c|c|c|c|c|c|}
\hline \multicolumn{1}{|c|}{ Sample ID } & \multicolumn{2}{c|}{$\mathbf{~} \mathbf{R A F}_{\mathbf{1 0}}$} & \multicolumn{2}{c|}{$\mathbf{3 R A F}_{\mathbf{1 0}}$} & \multicolumn{2}{c|}{$\mathbf{6 R A F}_{\mathbf{1 0}}$} \\
\hline \multicolumn{1}{|c|}{ Orientation } & $\mathbf{L}$ & $\mathbf{T}$ & $\mathbf{L}$ & $\mathbf{T}$ & $\mathbf{L}$ & $\mathbf{T}$ \\
\hline TS $[\mathrm{MPa}]$ & $9.2 \pm 0.9$ & $8.6 \pm 0.4$ & $8.5 \pm 0.3$ & $7.1 \pm 0.4$ & $10.2 \pm 0.6$ & $6.8 \pm 0.4$ \\
\hline EB $[\%]$ & $1075 \pm 31$ & $1150 \pm 26$ & $705 \pm 23$ & $811 \pm 24$ & $82 \pm 18$ & $101 \pm 22$ \\
\hline $\mathrm{M} 10 \%[\mathrm{MPa}]$ & $1.4 \pm 0.06$ & $1.0 \pm 0.03$ & $7.9 \pm 0.5$ & $4.5 \pm 0.4$ & $8.9 \pm 0.03$ & $4.4 \pm 0.06$ \\
\hline $\mathrm{M} 100 \%[\mathrm{MPa}]$ & $2.5 \pm 0.16$ & $2.1 \pm 0.09$ & $3.8 \pm 0.14$ & $3.1 \pm 0.24$ & - & $3.8 \pm 0.09$ \\
\hline$E$ modulus $[\mathrm{MPa}]$ & $13 \pm 2.3$ & $10 \pm 1.8$ & $64 \pm 6.0$ & $43 \pm 8.3$ & $84 \pm 6.0$ & $48 \pm 8.3$ \\
\hline
\end{tabular}




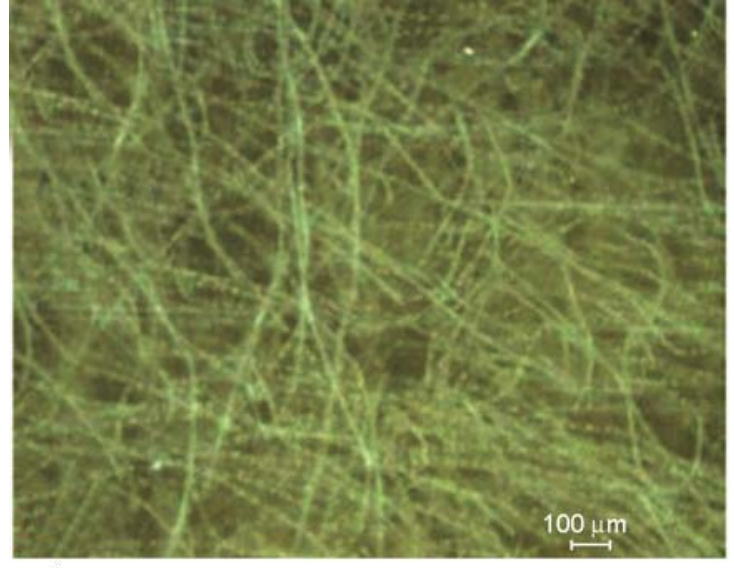

a)

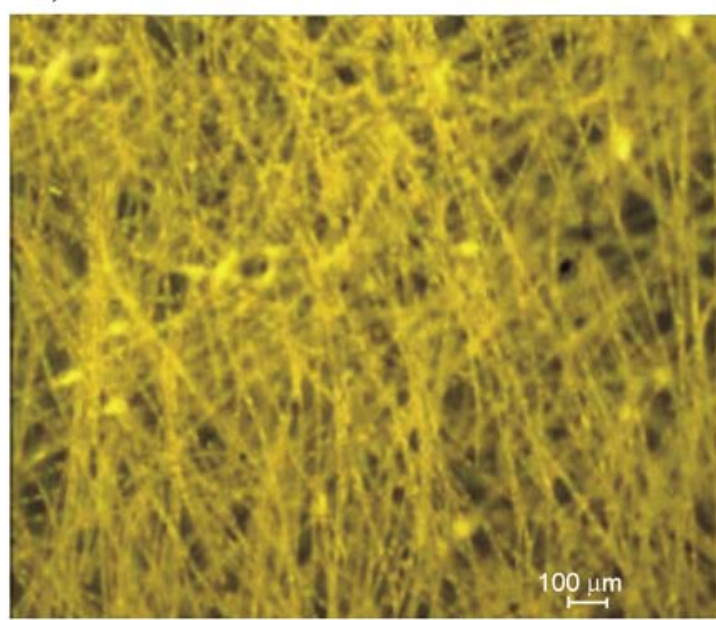

c)

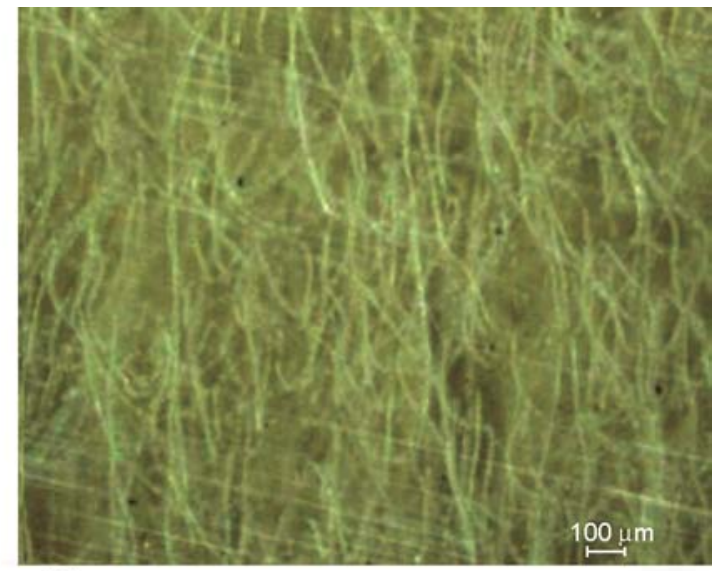

b)

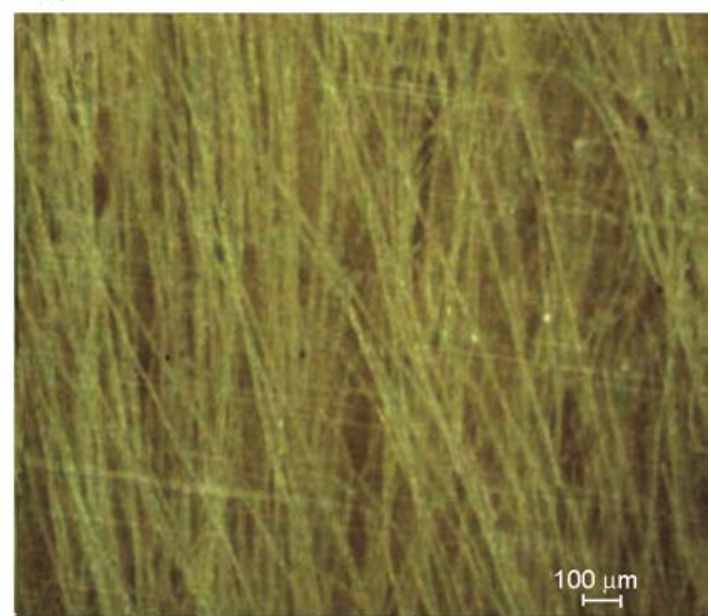

d)

Figure 4. Optical micrographs of $3 \mathrm{~mm} 5 \mathrm{phr}$ and $10 \mathrm{phr}$ loaded molded composites (a) and (c) before orientations and (b) and (d) after orientation. The scale bar shown here is $100 \mu \mathrm{m}$.

dispersion of $6 \mathrm{~mm}$ fiber at higher loading, we used MA-g-PB as a multifunctional dispersing agent. Lai et al. have explored the use of this as a compatibilizing agent to enhance interface interaction in nylon-6/ABS blends [36, 37]. From our earlier communication, we have done an optimization of the level of MA-g-PB based on the mechanical properties as $3 \mathrm{phr}$. The tensile stress vs strain ploat of $10 \mathrm{phr} 6 \mathrm{~mm}$ short fiber loaded composite before and after the addition of a 3 phr MA-g-PB is shown in Figure 5. From the figure it is clear that addition of MA-g-PB increases the area under the stressstrain curve by concomitantly increasing the ultimate tensile strength and the percentage break elongation without affecting Young's modulus. This observation suggests the potential use of MA-g-PB as an impact modifier to dissipate grater amount of energy before failure in the case of high length $(6 \mathrm{~mm})$ and high fiber loaded composite. It has also been observed that incorporation of MA-g-PB

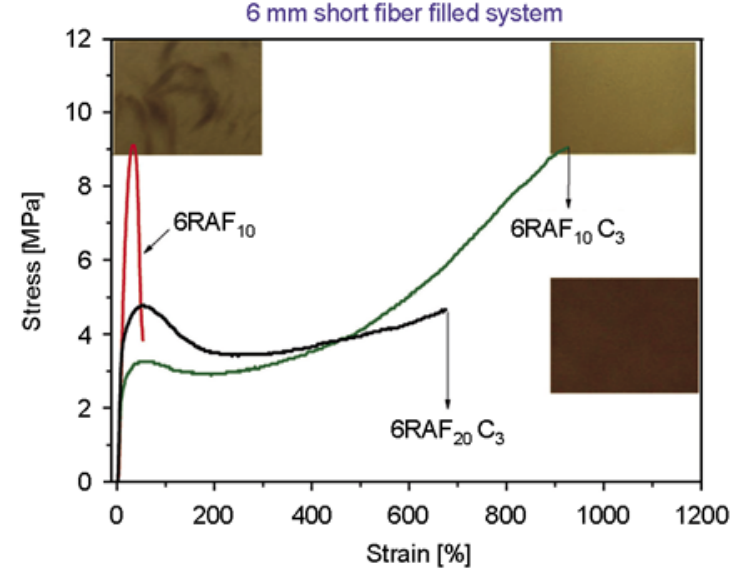

Figure 5. Stress-strain curves of $10 \mathrm{phr} 6 \mathrm{~mm}$ short fiber loaded composite $\left(6 \mathrm{RAF}_{10}\right), 6 \mathrm{~mm} 10 \mathrm{phr}$ short fiber loaded composite with 3 phr MA-g-PB $\left(6 \mathrm{RAF}_{10} \mathrm{C}_{3}\right)$ and $6 \mathrm{~mm} 20 \mathrm{phr}$ short fiber loaded composite with 3 phr MA-g-PB $\left(6 \mathrm{RAF}_{20} \mathrm{C}_{3}\right)$

tremendously improves the quality of fiber dispersion in the matrix as evidenced from the molded composite (shown as insets in Figure 5) which was 


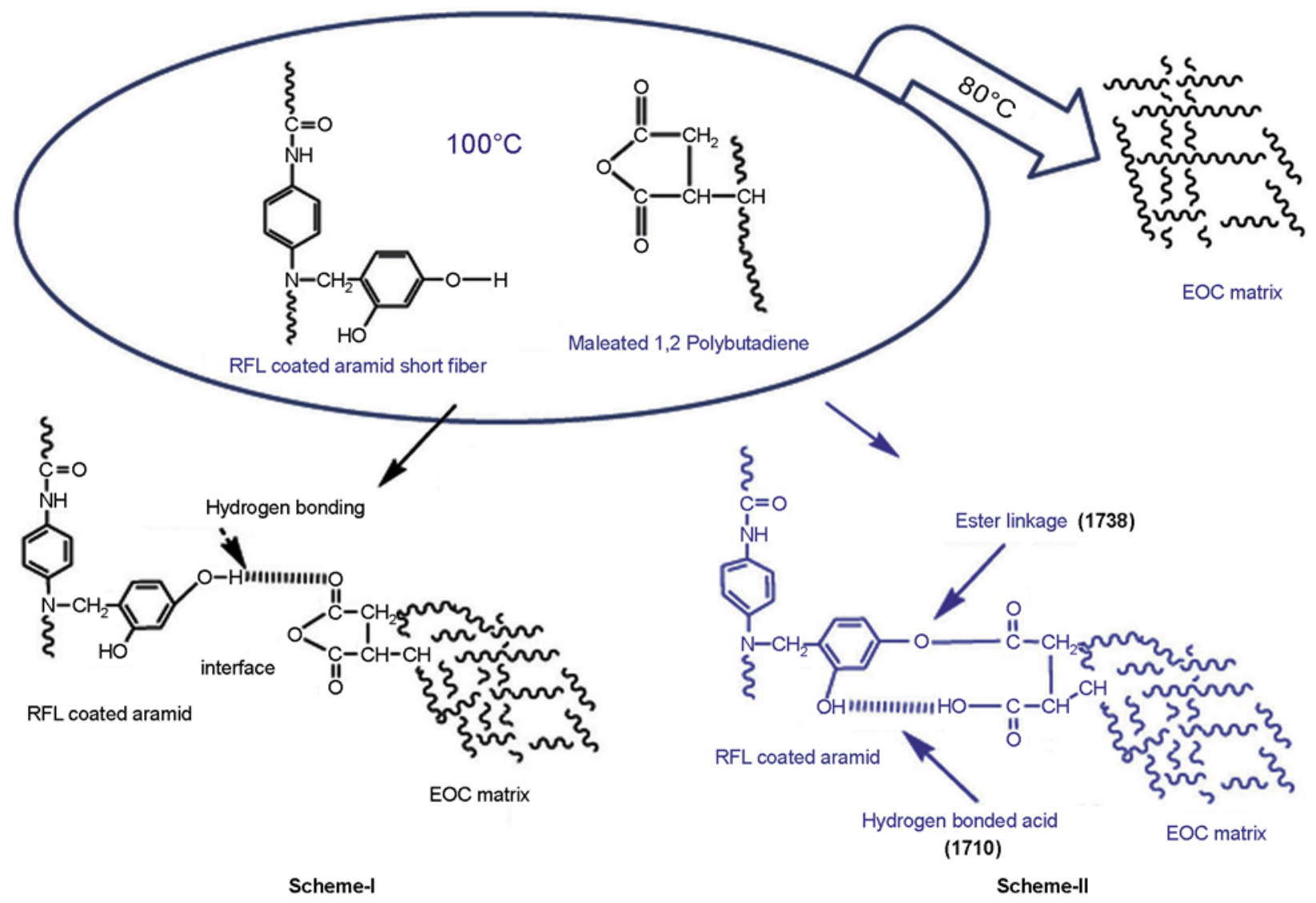

Figure 6. Plausible interaction mechanisms between MA-g-PB with RFL coated aramid fiber and the EOC matrix. Scheme I: Formation of H-bonding and Scheme II: Formation of ester linkages.

totally free from any kind of fiber aggregation to act as a stress concentrated points or failure points. A high quality of fiber dispersion could be easily achieved even in the case of a $20 \mathrm{phr} 6 \mathrm{~mm}$ fiber loaded composite. This uniform fiber dispersion could be one of the reasons for the improved tensile strength and elongation. Since the intake of $6 \mathrm{~mm}$ fiber loading gets enhanced with MA-g-PB without any dispersion problem, the toughness to stiffness balance of the composite can also be maintained with higher fiber loading, which is evident from the stress-strain behavior of $20 \mathrm{phr}$ fiber loaded composite with only 3 phr MA-g-PB shown in Figure 5. The enhancement in tensile strength coupled with elongation and a uniform fiber dispersion of the composites clearly indicate that the use of MA-gPB promotes the interfacial interaction. Figure 6 scheme I demonstrates one of the plausible expected interaction mechanism between the RFL coated aramid fiber and maleic anhydride adducted 1, 2 polybutadiene. It is believed that the butadiene segment (non polar) of MA-g-PB forms a compati- ble blend with the bulk EOC and the polar anhydride via the formation of H-bonds with the hydroxyl groups on the coated fibers and therefore forms a bridge at the interface between the two. This interface interaction enhances the stress transfer from the matrix to the fibers leading to higher tensile strength.

\subsection{Fourier transform infrared spectroscopy (FTIR)}

FTIR spectroscopy was used to explore the detailed chemical modification involved between RFL coated aramid fiber and MA-g-PB. Figure 7 shows the FTIR spectrum of (a) MA-g-PB, (b) RFL coated fiber and (c) MA-g-PB treated RFL coated fiber. The inset picture indicates an enlarged view between the frequency ranges of 1500 to $2000 \mathrm{~cm}^{-1}$. The characteristics bands correspond to the symmetrical $\left(1775 \mathrm{~cm}^{-1}\right)$ and asymmetrical $\left(1825 \mathrm{~cm}^{-1}\right)$ stretching frequencies generated from the $-\mathrm{CO}$-group of the anhydride part of MA-g-PB as shown in Figure $7 \mathrm{a}$. These peaks were found disappearing with the formation of new peaks at 1710 and $1737 \mathrm{~cm}^{-1}$ 


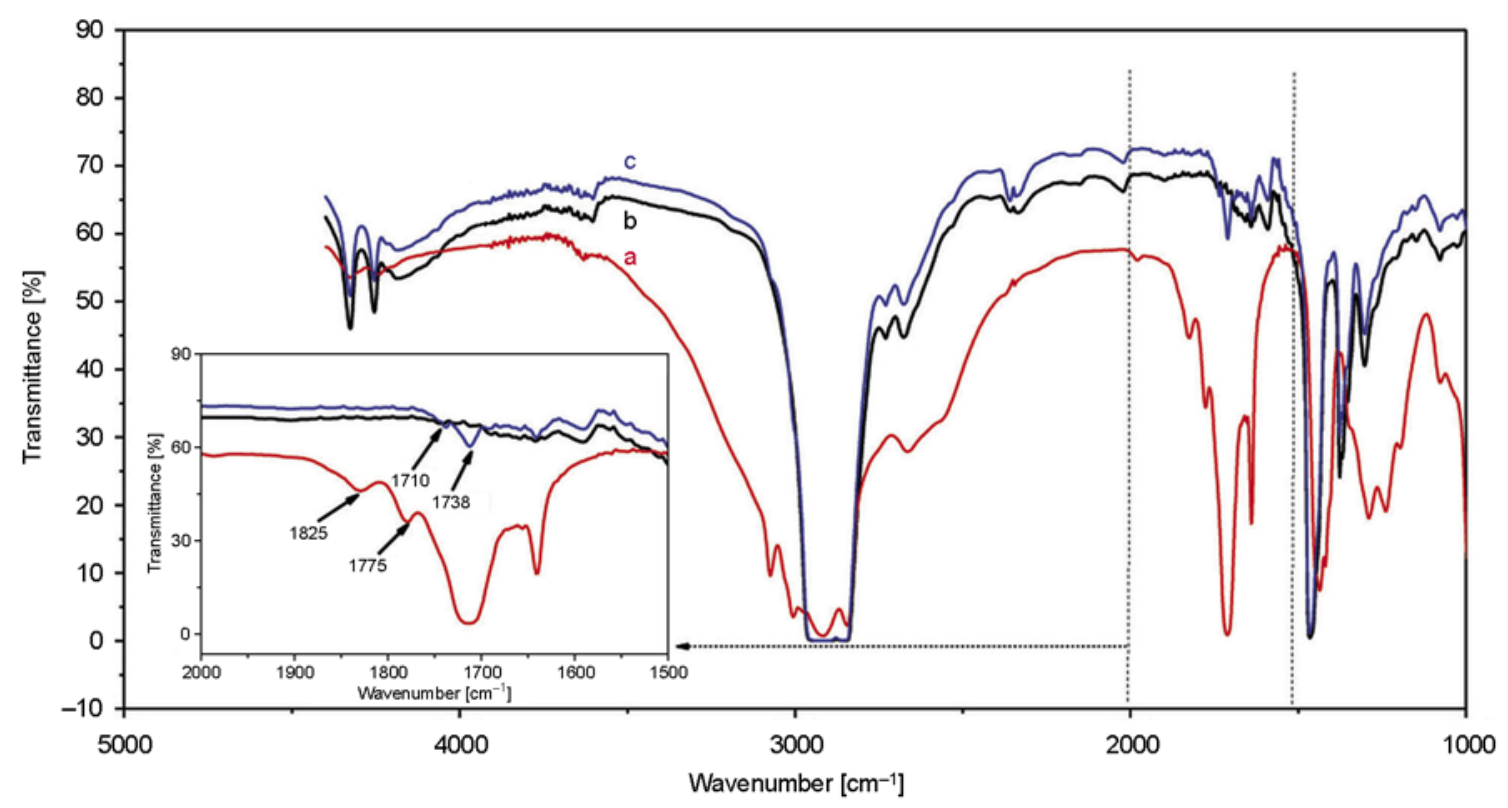

Figure 7. FTIR spectra of (a) pure MA-g-PB (b) RFL coated aramid short fiber (c) RFL coated aramid short fiber treated with MA-g-PB

when it was treated with RFL coated aramid fiber at $100^{\circ} \mathrm{C}$. The peaks at $1710 \mathrm{~cm}^{-1}$ indicate the hydrogen bonded acids and the peaks at $1737 \mathrm{~cm}^{-1}$ indicates the ester carbonyl groups [38]. Based on this FTIR result a new reaction mechanism is proposed as shown in scheme II of Figure 6. It is believed that when MA-g-PB is treated with RFL coated aramid fiber at $100^{\circ} \mathrm{C}$, the anhydride group of which gets converted into an ester by reacting with the hydroxyl group from the RFL coated fiber. A similar kind of interaction mechanism was reported by Liu and Dai [39] between jute fiber and MA-gPP emulsion. According to the expected mechanism shown in scheme I, if there is any H-bonding which exists between the functionalized fiber and the MA$\mathrm{g}-\mathrm{PB}$; the $-\mathrm{CO}-$ stretching frequencies of the anhydride group should have been shifted to a lower frequency side by a maximum of 5 to $10 \mathrm{~cm}^{-1}$. The non-occurrence of such a possibility may be due to the pronounced reaction as shown in scheme II and the difficulty in detect and distinguish the same due to very low concentration of MA-g-PB being used [40].

\subsection{SEM analyses}

In order to have a clear understanding of the effect of MA-g-PB on fiber dispersion in the matrix and its interface modifying effect for the improvement in tensile properties, the morphological analyses of the tensile fractured surface of a $6 \mathrm{~mm} 10 \mathrm{phr}$ loaded composite with and without MA-g-PB were performed under different magnifications. Figure 8a shows the distribution of fibers in the matrix without any MA-g-PB and Figure 8b shows the same with 3 phr of MA-g-PB. It is evident from the Figure $8 \mathrm{a}$ that the fibers were bunched together and agglomerate in the composite. An enlarged view of a portion of Figure 8a clearly indicates that some fibers get fibrillated at the fiber end to form tiny hair like fibers during shear mixing, which act as a twine to bind other fibers together and makes aggregate lumps [41]. This results the formation of some big voids on the matrix due to fiber pullout which leads to a brittle kind of failure of the composite when strain is applied. On the other hand, from Figure $8 \mathrm{~b}$ it is clear that after the addition of MA-g-PB, the fibers are evenly distributed in the matrix without any severe fiber aggregation. An enlarged view of a portion from Figure $8 \mathrm{~b}$, it is understood that, the MA-g-PB chemically bound on the fiber surface acts as a lubricant between the stiff fibers which reduces the friction between the fiber during shear mixing and enhance the wetting to disperse fibers more easily and evenly into the polymer matrix. In this case no fibrillation was observed causing any fiber aggregation. To understand the effectiveness of MA-g-PB as an interface modifying coupling agent, analyses were done on the proximal end of the fiber that is buried in the matrix which is in the process of pulling out from the matrix. Figure 9a shows one 

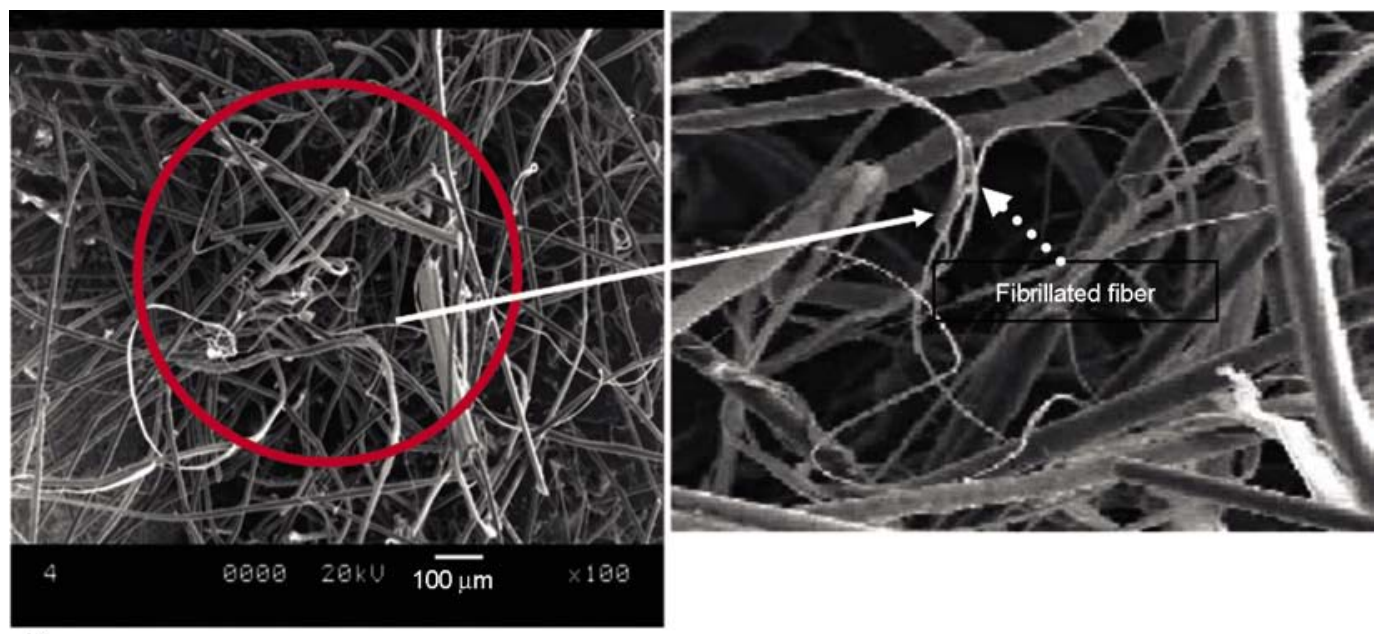

a)
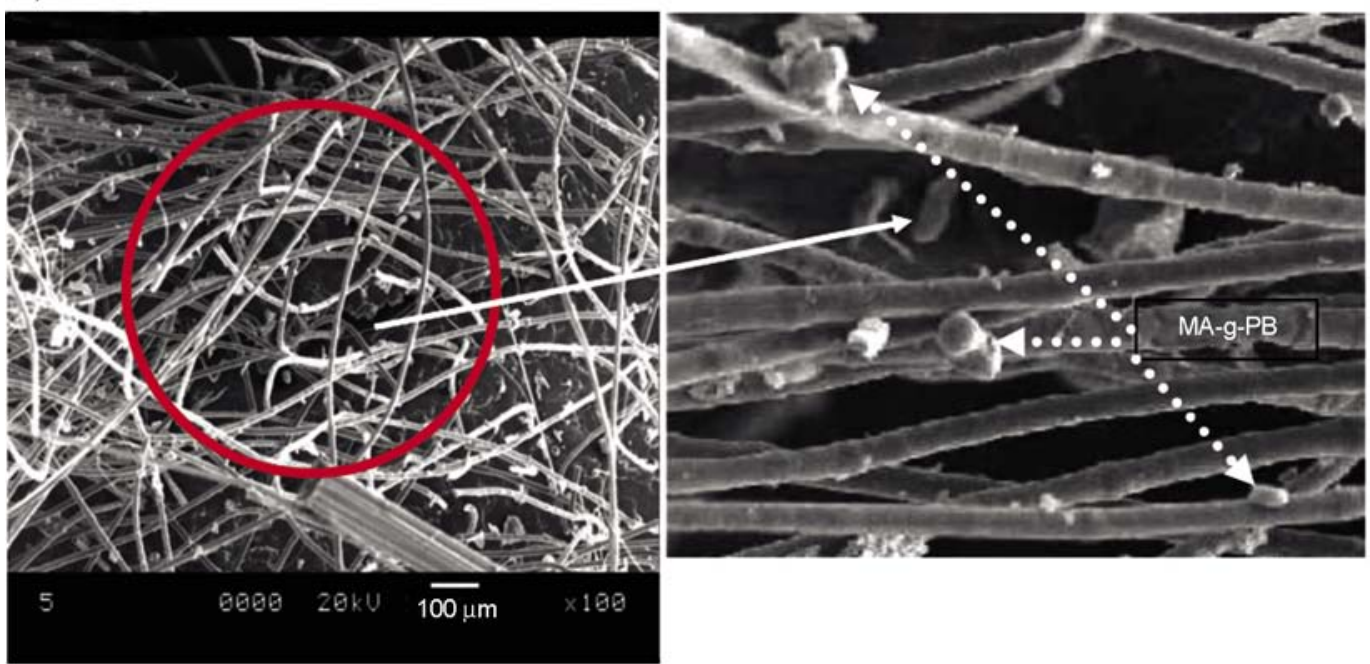

b)

Figure 8. SEM photomicrograph of tensile fractured surfaces of $10 \mathrm{phr} 6 \mathrm{~mm}$ short fiber loaded composites (a) without any treatment (b) with 3 phr MA-g-PB

such picture without any MA-g-PB and Figure 9b with 3 phr of MA-g-PB. A clear debonding gap can be seen at the interface between the fiber and the matrix in composite without any modifier, whereas a tight interface between the fiber and the matrix is established after the addition of MA-g-PB. This SEM observation strongly supports the improved fiber dispersion during the mixing process and the enhancement in tensile properties encountered during the tensile testing.

\subsection{Dynamic Mechanical Thermal Analyses (DMTA)}

DMA is an effective tool to determine the viscoelastic parameter, such as dynamic storage modulus $\left(E^{\prime}\right)$, glass transition temperature $\left(T_{\mathrm{g}}\right)$ and damping $(\tan \delta)$ characteristics of polymeric materials. Storage modulus is a measure of the maximum energy stored in the material during one cycle of oscillation. The $T_{\mathrm{g}}$ is defined as the region where storage modulus increases with increasing frequency at a constant temperature or the temperature at which maximum of the tan delta occurs. The ratio between the viscous modulus $\left(E^{\prime \prime}\right)$ to storage modulus is termed as tan delta, which is normally used to quantify the dissipation of the viscoelastic material. Figure $10 \mathrm{a}$ and $10 \mathrm{~b}$ show the variation of storage modulus $\left(E^{\prime}\right)$ and the loss factor $(\tan \delta)$ of neat EOC and its composite with a $3 \mathrm{~mm}$ aramid fiber having different concentrations as a function of temperature. It can be seen that the storage modulus of the composite is always higher than that of the neat matrix throughout the temperature range and is found to increase as the short fiber content increases. It is also evident from Figure 10b and Table 7 that the mechanical damping efficiency $(\tan \delta)$ of the 


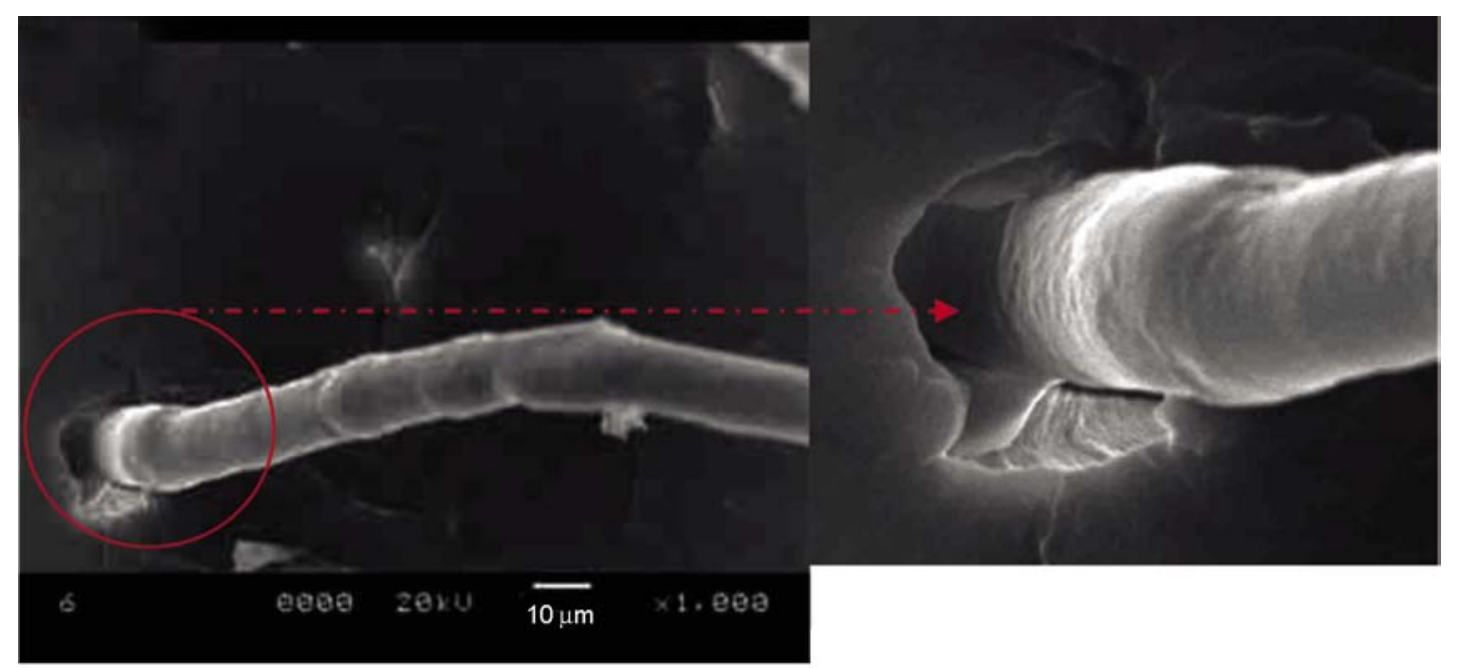

a)

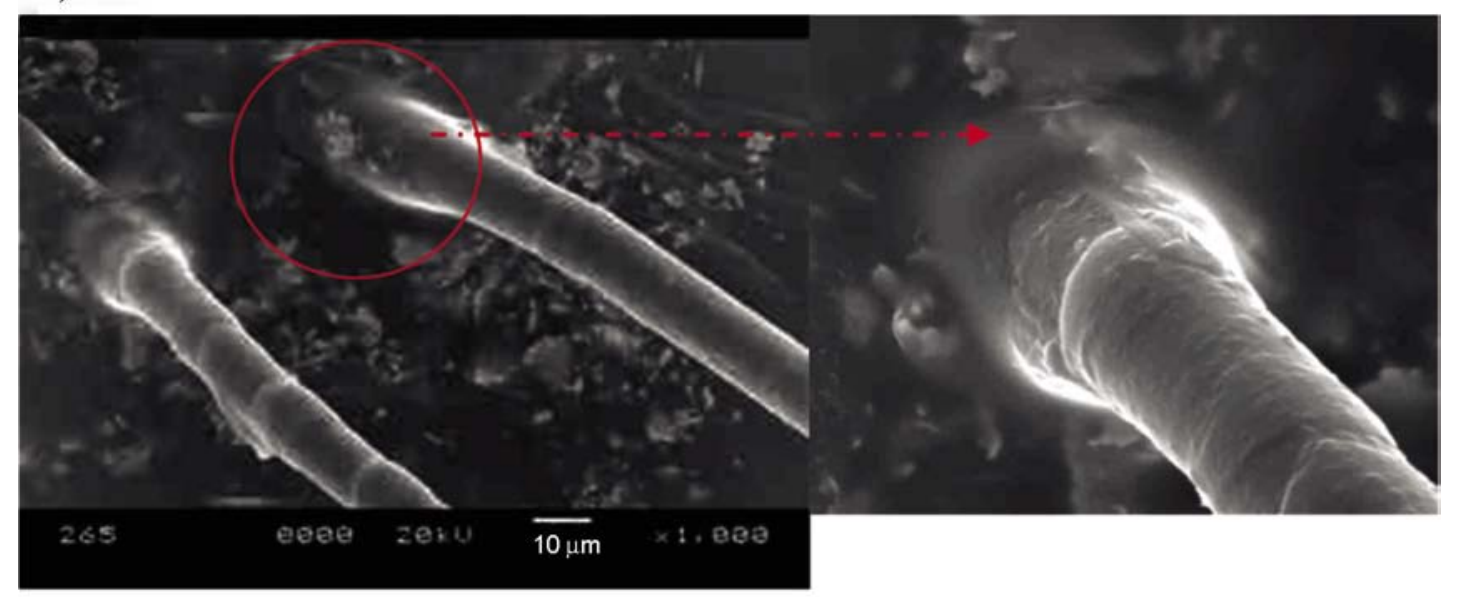

b)

Figure 9. SEM photomicrographs of tensile fractured surfaces of $10 \mathrm{phr} 6 \mathrm{~mm}$ short fiber loaded composite at the interface region (a) without any treatment (b) treated with 3 phr MA-g-PB

composites decreases as the fiber loading increase. The increase in $E^{\prime}$ and the decrease in tan delta peak height can be attributed to the restricted mobility of the polymer chain by the stiff fibers due to the reinforcement imparted by the fibers to the EOC

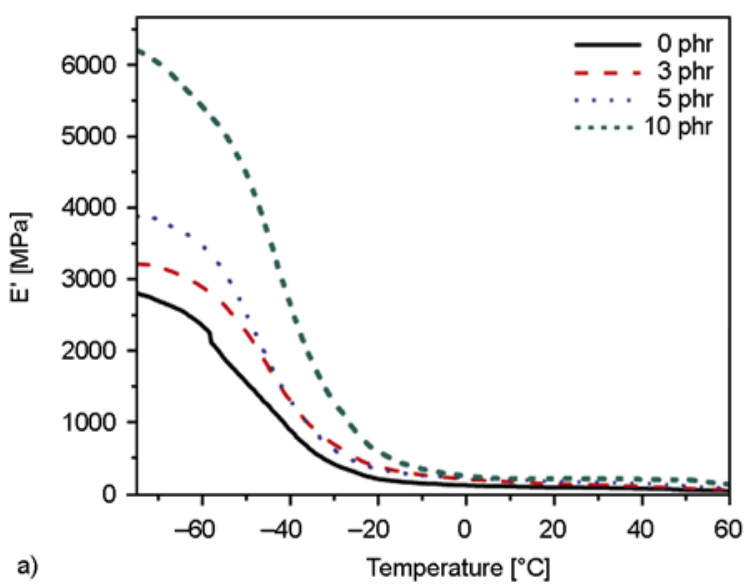

matrix. To get more insight into the reinforcement of EOC with aramid short fiber, the variation of storage modulus and the relative or normalized storage modulus at various temperatures as a function of fiber loading were analysed and is displayed

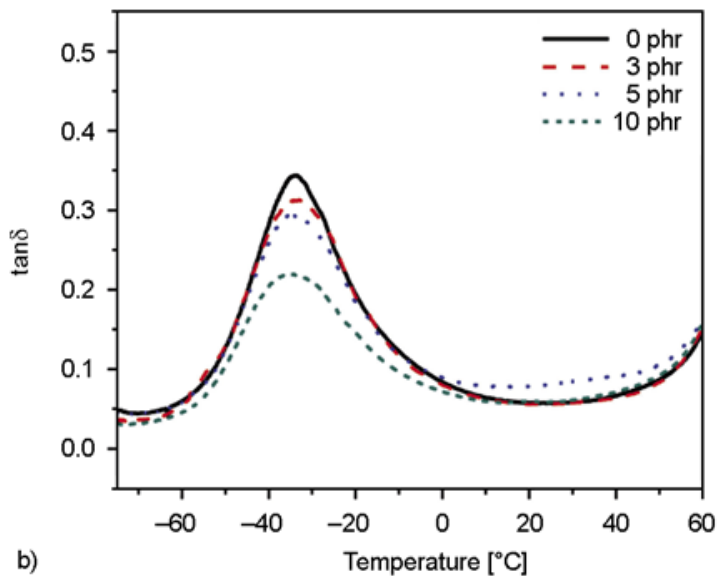

Figure 10. Dynamic mechanical properties of neat EOC and its composites with $3 \mathrm{~mm}$ short fiber as a function of fiber loading (a) storage modulus and (b) loss factor 
Table 7. Dynamic mechanical properties of the composites as a function of fiber loading

\begin{tabular}{|l|c|c|c|}
\hline \multicolumn{1}{|c|}{ Sample ID } & $\begin{array}{c}\mathbf{T}_{\mathbf{g}} \\
{\left[{ }^{\circ} \mathbf{C}\right]}\end{array}$ & Tano $_{\mathbf{m a x}}$ & $\begin{array}{c}\mathbf{E}^{\prime} \mathbf{a t} \mathbf{T}_{\mathbf{g}} \\
{[\mathbf{M P a}]}\end{array}$ \\
\hline Control & -33.7 & 0.34 & 531 \\
\hline $3 \mathrm{RAF}_{3}$ & -33.5 & 0.31 & 3169 \\
\hline $3 \mathrm{RAF}_{5}$ & -33.8 & 0.29 & 3226 \\
\hline $3 \mathrm{RAF}_{10}$ & -33.9 & 0.21 & 1697 \\
\hline
\end{tabular}

Table 8. Variation of storage modulus and normalized (relative) storage modulus as a function of fiber loading at different temperature

\begin{tabular}{|l|c|c|}
\hline \multicolumn{1}{|c|}{ Sample ID } & $\begin{array}{c}\mathbf{T}_{\mathbf{i}} \\
{\left[{ }^{\circ} \mathbf{C}\right]}\end{array}$ & $\begin{array}{c}\mathbf{T}_{\max } \\
{\left[{ }^{\circ} \mathbf{C}\right]}\end{array}$ \\
\hline Neat fiber & 487 & 510 \\
\hline Neat matrix & 376 & 442 \\
\hline $3 \mathrm{RAF}_{3}$ & 397 & 453 \\
\hline $3 \mathrm{RAF}_{5}$ & 408 & 461 \\
\hline $3 \mathrm{RAF}_{10}$ & 421 & 466 \\
\hline $1 \mathrm{RAF}_{5}$ & 409 & 463 \\
\hline $6 \mathrm{RAF}_{5}$ & 410 & 463 \\
\hline
\end{tabular}

in Table 8. From the table, it is clear that though the drop in modulus of the composite accelerates as the temperature increases, the relative or normalized drop in modulus decreases with increase in temperature. This may be due to the restriction of the polymer flow because of the fiber- matrix interaction. The effectiveness of Technora fiber on the improvement of storage modulus $\left(E^{\prime}\right)$ of EOC as a function of fiber loading was also evaluated on the basis of a coefficient ' $C$ ', using the Equation (1):

$C=\frac{\left(\frac{E_{\mathrm{g}}^{\prime}}{E_{\mathrm{r}}^{\prime}}\right) \operatorname{comp}}{\left(\frac{E_{\mathrm{g}}^{\prime}}{E_{\mathrm{r}}^{\prime}}\right) \text { resin }}$

where $E_{\mathrm{g}}^{\prime}$ and $E_{\mathrm{r}}^{\prime}$ are the storage modulus values in the glassy and rubbery regions respectively $[42,43]$. The base matrix used here is considered as the resin. The measured $E^{\prime}$ value at -33 and $20^{\circ} \mathrm{C}$ were used as $E_{\mathrm{g}}^{\prime}$ and $E_{\mathrm{r}}^{\prime}$ respectively. Generally the lower the value of the constant $C$, the higher is the effectiveness of filler as a reinforcing agent. In our system, the $C$ value of EOC/SF composite obtained for different fiber loading is given in Table 8. Lowering of ' $C$ ' value as a function of fiber loading indicates the effectiveness of aramid fiber as reinforcing filler for EOC matrix. The lowest values of $C$ at highest fiber loaded system indicates an efficient stress transfer from the matrix to fiber at this concentration.

\subsection{Thermal stability of the composites}

The thermogravimetric analyses has been performed to understand the degradation and the ther-
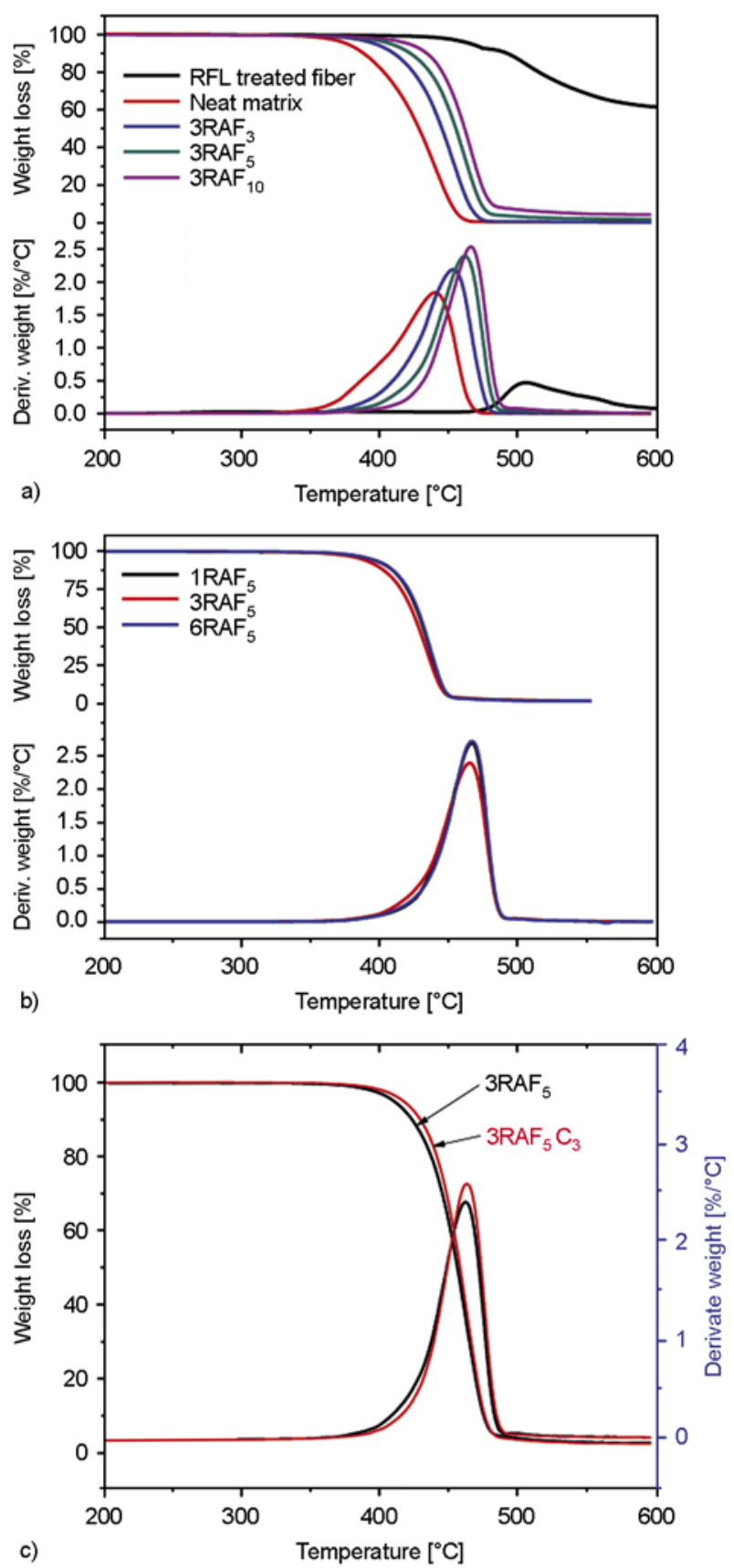

Figure 11. Thermogravimetric and the corresponding differential thermogravimetric curves (DTG): (a) neat EOC matrix, aramid fiber and its composites with $3 \mathrm{~mm}$ short fiber as a function of fiber loading (b) $5 \mathrm{phr}$ short fiber loaded composites as a function of fiber length (c) $3 \mathrm{~mm}$ $5 \mathrm{phr}$ loaded composite with $3 \mathrm{phr}$ of MA-g-PB 
Table 9. Thermogravimetric analyses of the composites as a function of fiber loading and length

\begin{tabular}{|c|c|c|c|c|c|c|c|}
\hline \multirow[t]{2}{*}{ Sample ID } & \multicolumn{3}{|c|}{$\begin{array}{c}\text { Storage modulus }\left(\mathrm{E}^{\prime}\right) \text { at various } \\
\text { temperature } \\
{[\mathrm{MPa}]}\end{array}$} & \multicolumn{3}{|c|}{$\begin{array}{c}\text { Relative storage modulus }\left(\mathrm{E}_{\mathrm{r}}{ }^{\prime}\right) \text { at various } \\
\text { temperature } \\
{[\mathrm{MPa}]}\end{array}$} & \multirow[t]{3}{*}{ C-value } \\
\hline & $20^{\circ} \mathrm{C}$ & $40^{\circ} \mathrm{C}$ & $60^{\circ} \mathrm{C}$ & $20^{\circ} \mathrm{C}$ & $40^{\circ} \mathrm{C}$ & $60^{\circ} \mathrm{C}$ & \\
\hline Control & 85 & 70 & 33 & 1 & 1 & 1 & \\
\hline $3 \mathrm{RAF}_{3}$ & 128 & 98 & 48 & 1.5 & 1.4 & 1.45 & 1.02 \\
\hline $3 \mathrm{RAF}_{5}$ & 168 & 140 & 69 & 1.97 & 2.01 & 2.10 & 0.85 \\
\hline $3 \mathrm{RAF}_{10}$ & 208 & 196 & 126 & 2.44 & 2.80 & 3.81 & 0.84 \\
\hline
\end{tabular}

mal stability of the composites as a function of short fiber loading and length. Figure 11a represents the thermogravimetric curves (TG) and the corresponding differential thermogravimertic curves (DTG) of neat EOC matrix, RFL dipped aramid short fiber and the composites of EOC/aramid fiber as a function of fiber loading at a fixed fiber length of $3 \mathrm{~mm}$. The TG and DTG curves obtained for the composites as a function of short fiber length at a fixed fiber loading of $5 \mathrm{phr}$ is given in Figure $11 \mathrm{~b}$. Single stage degradation peak was found in all the cases. Table 9 represents the onset of thermal degradation $\left(T_{\mathrm{i}}\right)$, maximum degradation temperature $\left(T_{\max }\right)$ and the maximum rate of degradation for the $\mathrm{EOC} /$ Sort fiber composite as a function of fiber length and loading. It is evident from the Table 9 that the point of onset of degradation of the neat EOC is shifted from 376 to $397^{\circ} \mathrm{C}$ with the addition of only $3 \mathrm{phr}$ of short fiber and is further increased to $421^{\circ} \mathrm{C}$ at $10 \mathrm{phr}$ fiber loading. Moreover, the maximum degradation temperature of EOC is also shifted to a higher temperature regime with the incorporation of the short fiber and is increased further as a function of fiber loading. These results confirm that the thermal stability of the EOC has been tremendously improved with the incorporation of short aramid fiber. This improvement in thermal stability can be attributed to the inherent high temperature stability of the aramid fiber and its reinforcing effect on EOC matrix. From the Figure $11 \mathrm{~b}$ it is clear that variation of short fiber length does not have any significant influence on the thermal degradation behavior of the composite. The incorporation of the MA-g-PB (Figure 11) also doesn't make any significant changes in the thermal behavior of the composite.

\section{Conclusions}

EOC/short aramid fiber composites were developed with three different fiber lengths (1,3 and $6 \mathrm{~mm}$ ) and the mechanical and thermomechanical properties were evaluated in presence of an interface modifying coupling agent. From our observations and analyses the following conclusions can be drawn:

(I) Incorporation of $1 \mathrm{~mm}$ short fiber does not affect the original deformation behavior and the mechanical properties to a significant level; however, it offers good thermal stability.

(II) $3 \mathrm{~mm}$ short fiber loaded composite shows an overall good balance in mechanical properties, fiber dispersion and the thermal properties at a fiber loading of $5 \mathrm{phr}$.

(III) $6 \mathrm{~mm}$ short fiber loaded composite increases the stiffness and thermal stability of the composite by sacrificing the toughness due to severe fiber aggregation.

(IV) The thermal stability of the composite increases with short fiber loading but, it is independent of fiber length.

(V) The stress-strain behavior, FTIR analyses and the morphological studies of the tensile fractured surfaces of $6 \mathrm{~mm}$ short fiber filled composite in presence of MA-g-PB strongly support its efficiency as a potential interface modifier as well as a fine dispersing agent for EOC/ Short fiber composite. The intake of $6 \mathrm{~mm}$ fiber loading gets enhanced in presence of MA-g-PB without any dispersion problem. It can be used as an impact modifier to maintain the toughness to stiffness balance of the composite using higher fiber loading which is evident from the stress-strain behavior of $20 \mathrm{phr}$ fiber loaded composite with only 3 phr of MA-g-PB. 


\section{Acknowledgements}

The authors are thankful to Teijin Aramid BV, The Netherlands for providing the Technora short fibres.

\section{References}

[1] Legge N. R., Holden G., Schroeders H. E.: Thermoplastic elastomer: A comprehensive review. Hanser, Munich (1987).

[2] Jiri G. D.: Handbook of thermoplastic elastomers. Wiliam Andrew Publishers, Norwich (2007).

[3] McNally T., McShane P., Nally G. M., Murphy W. R., Cook M., Miller A.: Rheology, phase morphology, mechanical, impact and thermal properties of polypropylene/metallocene catalysed ethylene 1-octene copolymer blend. Polymer, 43, 3785-3793 (2002). DOI: 10.1016/S0032-3861(02)00170-2

[4] Da Silva A. L. N., Rocha M. C. G., Coutinho F. M. B., Bretas R., Scuracchio C.: Rheological, mechanical, thermal, and morphological properties of polypropylene/ethylene-octene copolymer blends. Journal of Applied Polymer Science, 75, 692-704 (2000).

DOI: $10.1002 /($ SICI $) 1097-4628(20000131) 75: 5<692:$ : AID-APP12>3.0.CO;2-Y

[5] Svoboda P., Theravalappil R., Svobodova D., Mokrejs P., Kolomaznik K., Mori K., Ougizawa T., Inoue T.: Elastic properties of polypropylene/ethylene-octene copolymer blends. Polymer Testing, 29, 742-748 (2010).

DOI: 10.1016/j.polymertesting.2010.05.014

[6] Babu R. R., Singha N. K., Naskar K.: Interrelationships of morphology, thermal and mechanical properties in uncrosslinked and dynamically crosslinked PP/ EOC and PP/EPDM blends. Express Polymer Letters, 4, 197-209 (2010).

DOI: $10.3144 /$ expresspolymlett.2010.26

[7] Babu R. R., Singha N. K., Naskar K.: Studies on the influence of structurally different peroxides in polypropylene/ethylene alpha olefin thermoplastic vulcanizates (TPVs). Express Polymer Letters, 2, 226-236 (2008).

DOI: $10.3144 /$ expresspolymlett.2008.27

[8] Chapleau N., Huneault M. A.: Impact modification of poly(ethylene terephthalate). Journal of Applied Polymer Science, 90, 2919-2932 (2003).

DOI: $10.1002 /$ app. 13016

[9] Aróstegui A., Nazábal J.: Super-toughness in compatibilized poly(butylene terephthalate)/poly(ethyleneoctene) copolymer blends. Polymer Engineering and Science, 43, 1691-1701 (2003).

DOI: $10.1002 /$ pen.10143

[10] Uthaman N. R., Pandurangan A., Majeed S. M. A.: Blends of polyacetal end ethylene-octene elastomer: Mechanical, dynamic mechanical and morphological properties. Journal of Polymer Research, 14, 441-447 (2007).

DOI: $10.1007 / \mathrm{s} 10965-007-9126-6$
[11] Guerrica-Echevarría G., Eguiazábal J. I., Nazábal J.: Influence of compatibilization on the mechanical behavior of poly(trimethylene terephthalate)/poly(ethylene-octene) blends. European Polymer Journal, 43, 1027-1037 (2007).

DOI: 10.1016/j.eurpolymj.2006.11.036

[12] Yu Z-Z., Ou Y-C., Hu G-H.: Influence of interfacial adhesion on toughening of polyethylene-octene elastomer/nylon 6 blends. Journal of Applied Polymer Science, 69, 1711-1718 (1998).

DOI: 10.1002/(SICI)1097-4628(19980829)69:9<1711 $\because$ AID-APP4>3.0.CO;2-E

[13] De S. K., White J. R.: Short fiber polymer composites. Woodhead, Cambridge (1996).

[14] Chantaratcharoen A., Sirisinha C., Amornsakchai T., Bualek-Limcharoen S., Meesiri W.: Improvement of interfacial adhesion of poly $(m$-phenylene isophthalamide) short fiber-thermoplastic elastomer (SEBS) composites by $\mathrm{N}$-alkylation on fiber surface. Journal of Applied Polymer Science, 74, 2414-2422 (1999).

DOI: 10.1002/(SICI)1097-4628(19991205)74:10<2414 $\because$ AID-APP9>3.0.CO;2-V

[15] Ahamad I., Chin T. S., Cheong C. K., Jalar A., Abdullah I.: Study of fiber surface treatment on reinforcement/matrix interaction in twaron fiber/ENR composites. American Journal of Applied Sciences (Special Issue), 14-20 (2005).

[16] Mori M., Uyama Y., Ikada Y.: Surface modification of aramid fiber by graft polymerization. Polymer 35, 5336-5341 (1994).

DOI: 10.1016/0032-3861(94)90487-1

[17] Amornsakchai T., Sinpatanapan B., Bualek-Limcharoen S., Meesiri W.: Composite of aramid fibre (poly- $m$-phenylene isophthalamide)-thermoplastic elastomers (SEBS): Enhancement of tensile properties by maleated-SEBS compatibiliser. Polymer, 40, 29932999 (1999).

DOI: $10.1016 / \mathrm{s} 0032-3861(98) 00524-2$

[18] Arroyo M., Bell M.: Morphology/behavior relationship and recyclability of composites based on PP/ EPDM blends and short aramid fibers. Journal of Applied Polymer Science, 83, 2474-2484 (2002).

DOI: $10.1002 / a p p .10244$

[19] Kutty S. K. N., Nando G. B.: Short kevlar fiber-thermoplastic polyurethane composites. Journal of Applied Polymer Science, 43, 1913-1923 (1991).

DOI: 10.1002/app.1991.070431016

[20] Kutty S. K. N., Chaki T. K., Nando G. B.: Thermal degradation of short kevlar fibre thermoplastic polyurethane composite. Polymer Degradation and Stability, 38, 187-192 (1992). DOI: 10.1016/0141-3910(92)90113-J

[21] Akbarian M., Hassanzadeh S., Moghri M.: Short twaron aramid fiber reinforced thermoplastic polyurethane. Polymers for Advanced Technologies, 19, 1894-1900 (2008).

DOI: $10.1002 /$ pat. 1225 
[22] Cerrada M. L., Benavente R., Pérez E.: Effect of short glass fiber on structure and mechanical behavior of an ethylene-1-octene copolymer. Macromolecular Chemistry and Physics, 202, 2686-2695 (2001).

DOI: 10.1002/1521-3935(20010901)202:13<2686:: AID-MACP2686>3.0.CO;2-L

[23] Cerrada M. L., Benavente R., Pérez E.: Crystalline structure and viscoelastic behavior in composites of a metallocenic ethylene-1-octene copolymer and glass fiber. Macromolecular Chemistry and Physics, 203, 718-726 (2002).

DOI: $10.1002 / 1521-3935(20020301) 203: 4<718:: A I D-$ MACP718>3.0.CO;2-S

[24] Shibulal G. S., Naskar K.: RFL coated aramid short fiber reinforced thermoplastic elastomer: Mechanical, rheological and morphological characteristics. Journal of Polymer Research, 18, 2295-2306 (2011). DOI: $10.1007 / \mathrm{s} 10965-011-9643-1$

[25] Akhtar S., De P. P., De S. K.: Short fiber-reinforced thermoplastic elastomers from blends of natural rubber and polyethylene. Journal of Applied Polymer Science, 32, 5123-5146 (1986).

DOI: $10.1002 / a p p .1986 .070320530$

[26] Folkes M. J.: Short fiber reinforced thermoplastics. Wiley, New York (1982).

[27] Chang A., Cheung Y. W., Hiltner A., Baer E.: Relationship of deformation behavior to thermal transitions of ethylene/styrene and ethylene/octene copolymers. Journal of Polymer Science Part B: Polymer Physics, 40, 142-152 (2002).

DOI: $10.1002 /$ polb.10066

[28] Tripathi D., Jones F. R.: Single fibre fragmentation test for assessing adhesion in fibre reinforced composites. Journal of Materials Science, 33, 1-16 (1998). DOI: 10.1023/A:1004351606897

[29] Androsch R., Stribeck N., Lüpke T., Funari S. S.: Investigation of the deformation of homogeneous poly(ethylene-co-1-octene) by wide- and small-angle $\mathrm{X}$-ray scattering using synchrotron radiation. Journal of Polymer Science Part B: Polymer Physics, 40, 1919-1930 (2002).

DOI: $10.1002 /$ polb.10243

[30] Tarfaoui M., Choukri S., Neme A.: Effect of fibre orientation on mechanical properties of the laminated polymer composites subjected to out-of-plane high strain rate compressive loadings. Composites Science and Technology, 68, 447-485 (2008).

DOI: $10.1016 /$ j.compscitech.2007.06.014

[31] Jang J., Kim H.: Improvement of carbon fiber/PEEK hybrid fabric composites using plasma treatment. Polymer Composites, 18, 125-132 (1997). DOI: $10.1002 /$ pc. 10267

[32] Mathew L., Joseph R.: Mechanical properties of shortisora-fiber-reinforced natural rubber composites: Effects of fiber length, orientation, and loading; alkali treatment; and bonding agent. Journal of Applied Polymer Science, 103, 1640-1650 (2007).

DOI: $10.1002 /$ app. 25065
[33] Mahy J., Jenneskens L. W., Grabandt O.: The fibre/ matrix interphase and the adhesion mechanism of surface-treated Twaron ${ }^{\circledR}$ aramid fibre. Composites, 25, 653-660 (1994).

DOI: 10.1016/0010-4361(94)90198-8

[34] Mäder E., Freitag K-H.: Interface properties and their influence on short fibre composites. Composites, 21, 397-402 (1990).

DOI: 10.1016/0010-4361(90)90437-2

[35] Guigon M., Klinklin E.: The interface and interphase in carbon fibre-reinforced composites. Composites, 25, 534-539 (1994). DOI: 10.1016/0010-4361(94)90181-3

[36] Lai S-M., Liao Y-C., Chen T-W.: The preparation and properties of compatibilized nylon 6/ABS blends using functionalized polybutadiene. Part I: Impact properties. Polymer Engineering and Science, 45, 1461-1470 (2005).

DOI: $10.1002 /$ pen.20428

[37] Lai S-M., Li H-C., Liao Y-C.: Properties and preparation of compatibilized nylon 6 nanocomposites/ABS blends: Part II - Physical and thermal properties. European Polymer Journal, 43, 1660-1671 (2007). DOI: 10.1016/j.eurpolymj.2007.02.009

[38] Rajput R. S., Rupainwar D. C., Sing A.: A study on styrene maleic anhydride modification by benzoic acid derivatives and dimethyl sulfoxide. International Journal of Chemical Technology, 4, 915-919 (2009).

[39] Liu X. Y., Dai G. C.: Surface modification and micromechanical properties of jute fiber mat reinforced polypropylene composites. Express Polymer Letters, 5, 299-307 (2007).

DOI: $10.3144 /$ expresspolymlett.2007.43

[40] Zeng Z., Ren W., Xu C., Lu W., Zhang Y., Zhang Y.: Maleated natural rubber prepared through mechanochemistry and its coupling effects on natural rubber/ cotton fiber composites. Journal of Polymer Research, 17, 213-219 (2009).

DOI: $10.1007 / \mathrm{s} 10965-009-9307-6$

[41] Hashimoto A., Satoh M., Iwasaki T., Morita M.: Fibrillation of aramid fiber using a vibrating ball mill and evaluation of the degree of fibrillation. Journal of Materials Science, 37, 4013-4017 (2002).

DOI: 10.1023/A:1019696614997

[42] Praveen S., Chattopadhyay P. K., Jayendran S., Chakraborty B. C., Chattopadhyay S.: Effect of nanoclay on the mechanical and damping properties of aramid short fibre-filled styrene butadiene rubber composites. Polymer International, 59, 187-197 (2010). DOI: $10.1002 /$ pi.2706

[43] Sreekumar P. A., Saiah R., Saiter J. M., Leblanc N., Joseph K., Unnikrishnan G., Thomas S.: Dynamic mechanical properties of sisal fiber reinforced polyester composites fabricated by resin transfer molding. Polymer Composites, 30, 768-775 (2009).

DOI: $10.1002 /$ pc.20611 